\title{
Psychological Counseling Training to Improve the Psychological Quality of College Students
}

\author{
Zhuang Yaling ${ }^{1, a}$ \\ ${ }^{1}$ Department of moral education, Yantai Vocational College, Yantai, Shandong 264025, China \\ àzhuangling@126.com
}

Keywords: psychological counseling training; college students; psychological quality; practice exploration

\begin{abstract}
Psychological counselling training is an important clinical psychological intervention method, which can effectively improve and optimize the healthy psychological quality of college students. This paper first analyzes the basic meaning, characteristics and significance of psychological counselling training, explores the application of psychological counseling training in college education, and focuses on the influence of different psychological counselling methods on the psychological quality of college students, and puts forward a kind of group psychological counseling and individual psychology as the main means. It is of great significance for college students to improve their psychological quality, enhance their adaptability, improve their interpersonal relationship, and manage their learning emotions.
\end{abstract}

\section{Introduction}

At present, because of the late start, less attention and weak support, the level and the scale of the college students' psychological guidance and training are still difficult to meet the demand for the psychological problems of the new age college students [1]. In order to improve the psychological quality of the contemporary college students and train the all-round developing high-quality talents for the modernization of our country, the university should pay full attention to the psychological guidance work of the college students, and increase the support of the funds and manpower. In the light of the psychological health of the college students, the scientific and effective guidance plan is put into practice. We should promote the construction of mental health of college students, and strive to achieve some achievements and breakthroughs. On the basis of in-depth understanding and analysis of the existing achievements, this paper makes an innovation on the application of psychological guidance training and has obtained some theoretical results.

\section{Analysis of Psychological Counseling Training}

\subsection{The meaning of psychological counselling training}

Psychological guidance refers to improving the sense of trust and belonging by the professional mentors in a certain psychological environment through proper guidance to the relevant members, helping to realize self-cognition and self-exploration, gradually improving the interpersonal relationship and improving the adaptability, and finally achieving the goal of preventing and solving all kinds of psychological problems. According to the different range of application of psychological counselling training, it can be divided into group psychological counseling and individual psychological counseling. The two are interrelated and different. Compared with individual psychological counselling, group counseling pays more attention to the interaction between individuals receiving psychological guidance in the process of psychological guidance. In the process of individual psychological counseling, the tutor needs to focus on different sex, age, people, family economic conditions, parents or single parents. Students with family or parents divorced, rural areas 
or cities have targeted psychological counselling. How to adopt or avoid the influence of the relationship between the group psychological guidance on the psychological quality change and how to apply effective psychological guidance to the students with different background conditions is a problem worthy of further discussion, and a higher requirement for the tutor who exerts psychological training is [2].

\subsection{Characteristics of Psychological Counselling Training}

\subsubsection{Influential tutorship}

The psychological guidance training has established an effective communication channel between the tutor and the college students, and the college students will take a multi angle examination and cognition in their psychological process under the guidance of the tutor's situational guidance and imitation adaptation. The training of psychological guidance requires not only the tutors' deep guidance and help to the students, but also the strong sense of trust and belonging of the students to the tutors, the school, the surrounding students and the society as a whole.

\subsubsection{Targeted tutoring}

In view of different guidance objects, specific analysis of specific problems should be carried out by individual psychological guidance or group counseling, so as to achieve higher guidance efficiency. Because there are many similarities between mental health and psychological problems of college students in China, there are many differences caused by individual differences. It is necessary for mentors to carry out a targeted analysis to carry out a unified group psychological assistance for students with similar psychological problems or psychological disturbances. At the same time, the students who have special psychological problems or psychological troubles carry out individual psychological guidance to make the limited manpower and time exerting the maximum efficiency.

\subsubsection{Related coaching}

Psychological guidance will show the real social life situation and create a good social atmosphere. In this process, college students also show their daily life and behavior, and carry out normal interpersonal communication. Mentors need to establish a trust relationship with the tutored individual in such an environment, or to create a good interpersonal relationship with the people around them, and better conduct psychological counseling in an environment that is connected to each other.

\subsubsection{Highlight key guidance}

Due to some subjective and objective reasons, some college students can not have an objective understanding and evaluation of themselves. It is difficult for others to form sufficient trust, thus affecting the establishment of good interpersonal relationship. In the process of psychological counseling, whether group psychological guidance or individual psychological guidance, the tutor needs to focus on the group or individual with poor interpersonal adaptability, and help this kind of people not adapt to interpersonal relationship to improve their psychological quality, so as to achieve better psychological guidance effect.

\subsection{The significance of psychological counselling training}

Practice shows that psychological counselling is of great significance for building healthy psychological quality of college students, mainly in the following three aspects:

\subsubsection{Psychological counseling can play a good role in communication and education.}

Good psychological quality and better communication environment can make the college students study actively, improve their knowledge reserve and social practice ability, so that they can more easily understand and explore the various problems in the profession from the perspective of practice. Compared with the traditional way of education, psychological counseling meets the requirements of College Students' education, and has achieved excellent educational communication results. 


\subsubsection{Psychological counseling can solve the psychological problems of most college students.}

There are certain commonalities among college students, and the differences in psychological problems they face are relatively small. In view of some common problems, a reasonable way of psychological counseling can enable most college students to solve similar problems at the same time. Therefore, the psychological counseling for college students is more efficient, and can often achieve good results.

\subsubsection{Psychological counseling is conducive to communication among peers.}

For college students, traditional inculcation education tends to show some resistance psychology. Through communication with mentors or members of the tutored group, we can share the successful experience of improving each other's psychological quality, explore effective ways to solve each other's psychological quality problems, and better promote interaction between college students.

\section{The Application of Psychological Counseling Training}

\subsection{Typical application of psychological counselling training}

It is not uncommon to develop psychological counseling training methods and put them into action in the current ideological and political education in Colleges and universities.

\subsubsection{The group psychological guidance training help college students have the ability of self-adjusting psychological quality.}

In order to improve the psychological quality of self-adjustment, the psychological quality of college students can be promoted quickly, and the psychological quality of college students can be improved rapidly in the daily life, so that they have more mature psychological endurance and have strong practicability. The first step in the teaching process is to help you eliminate negative emotions. If college students are less able to adjust their negative emotions, they are easily affected by negative emotions, so that they do things impulsive, reckless, and can not concentrate their thoughts on some major problems, such as academic career and employment, which are extremely unfavorable to the later academic career. The solution of negative emotions can be explained clearly in class by giving up, self-suggestion and proper vent. After that, all the students are divided into groups, through the activities such as "I have words to say", "let everyone out" and other activities, through the group members in the activities to express their satisfaction or dissatisfaction in the recent period of time, so as to achieve the purpose of dredging the negative emotions. On this basis, a few teams are chosen, and the person in charge summarizes the speech at the discussion of negative emotions, and then explains how to cultivate the sense of responsibility of the college students and improve the communication skills among the students.

\subsubsection{The individual psychological counseling training help college students have the stronger psychological setback ability.}

It is necessary to clarify the number of students, the proportion of men and women, the average age, the study stage of the University and the current learning tasks. In the practice of individual psychological counseling training, we first master the psychological feedback of the individual to the current university environment, and give the students "psychological counseling self evaluation questionnaire", and list the typical psychological feedback summed up in the process of group counseling, and set up a very satisfactory, satisfactory and dissatisfied three level evaluation body in the expression level. The results of self-assessment questionnaire were statistically analyzed. The problems that are common and easy to solve in group counseling in the future can be explained according to the time of psychological counseling. For the problems that are rare and unfrequent in the current group counseling, we need to focus on the explanation in order to make a further understanding of the individual mental state, and have a pre psychological preparation for the 
difficulties and setbacks that may be encountered in the future. One's academic career is more confident.

\subsection{Application innovation of psychological counselling training}

From the typical cases of psychological counseling training, it is known that, to a certain extent, psychological guidance training can improve the psychological quality of college students in our country, but the psychological guidance work will be subject to problems such as funds, technology, personnel, ideas and organizations. While fully recognizing the important role of psychological guidance in Ideological Education in Colleges and universities, we should make full use of the existing conditions and implement effective psychological counseling. The following is the application of group counseling and individual psychological counseling.

\subsubsection{The group psychological counseling enhances college students' trust in others and their ability to adapt to collectives.}

By creating a good atmosphere for group counseling, we can create conditions for college students to improve their emotional experience. In groups, we can recognize each other's commonalities, feel the collective acceptance and warmth, and thus be hopeful of improving their psychological quality. In addition, under the influence of group cohesion, collective consciousness and trust are enhanced, which can make it easier for individuals to lay down their psychological burden and integrate into collective life and interpersonal communication with a relaxed and steady state of mind. For example, you can organize a small game of "falling back". A student falls in a certain direction in a state of losing weight. The students gathered around it quickly concentrate and support the students who fall down. At the same time, the participants feel the support and protection of the collective, and get rid of the negative feelings of fear and loneliness. Pessimism strengthens college students' trust in others and their ability to adapt to collectives.

\subsubsection{The individual psychological counseling enhances college students' self-confidence.}

Due to the lack of objective self-evaluation, some students may have psychological problems of lack of self-confidence. The individual psychological guidance needs to guide the students with different personality and psychological problems to correctly guide them to produce objective and correct self-awareness and evaluation, thus producing a series of psychological concepts of chain transformation. In the first steps, a harmonious collective atmosphere has been set up in the first implementation step, and the feeling of warmth, security and dependence has been created. On this basis, it is necessary to emphasize the indispensible nature of the individual and make it more confident, which is of great significance and function to the improvement of psychological problems. For example, when cultivating students' communicative initiative and correct communication skills, some "psychological short play" can be designed to encourage students to speak freely and actively into interpersonal relationship performance, so that they can understand the true meaning of interpersonal communication and develop good communication habits and behaviors.

\section{Conclusion}

As the psychological guidance training has gradually become an important part of the ideological and political education in Colleges and universities, the practical thinking and ways of its application have been paid much attention by the researchers. This paper creatively puts forward the psychological counselling application group, which is mainly composed of group psychological counseling and individual psychological counseling. At the same time, in order to improve the effectiveness of individual psychological guidance and enhance the pertinence of psychological guidance and education, the psychological quality of College Students' groups can be guided by setting up psychological counselling courses and psychological tests to guide college students to create a sound psychological quality. This method can be widely applied in daily ideological and political education practice. 


\section{References}

[1] Wang Xiangdong. Wang Xilin. Mental health rating scale Handbook [M]. Beijing: Mental Health Journal, 1999:241 - 244.

[2] Li Jing, Wang Chuanjun, Liu Genyi, et al. The application of group psychological counseling in cultivating college students' interpersonal skills [J]. Chinese behavioral medicine science, 2001, 10 (6):616.

[3] Huang Lan. Analysis of the practice of psychological counseling in the ideological and political education of college students [J]. Journal of Southwest University for Nationalities (HUMANITIES AND SOCIAL SCIENCES), 2005 (3): 360-363. 